\title{
Corrigendum: Psychedelics as a Treatment for Alzheimer's Disease Dementia
}

\author{
Simon Andrew Vann Jones * and Allison O'Kelly \\ Cornwall Partnership NHS Foundation Trust, Liskeard, United Kingdom
}

Keywords: psychedelic, Alzheimer's disease, dementia, plasticicity, microdosing

\section{OPEN ACCESS}

Approved by:

Frontiers Editorial Office,

Frontiers Media SA, Switzerland

*Correspondence: Simon Andrew Vann Jones s.vannjones@nhs.net

Received: 16 September 2020 Accepted: 17 September 2020

Published: 26 October 2020

Citation:

Vann Jones SA and O'Kelly A (2020)

Corrigendum: Psychedelics as a

Treatment for Alzheimer's Disease Dementia.

Front. Synaptic Neurosci. 12:607194.

doi: $10.3389 /$ fnsyn.2020.607194

\section{A Corrigendum on}

Psychedelics as a Treatment for Alzheimer's Disease Dementia

by Vann Jones, S. A., and O'Kelly, A. (2020) Front. Synaptic Neurosci. 12:34. doi: 10.3389/fnsyn.2020.00034

In the original article, there was an error. In the "Neurophysiological effects" section, second paragraph, there was an error message in between two of the references: "Error! Bookmark not defined". All the references are present and correct.

A correction has been made to the "Neurophysiological effects" section, second paragraph. The sentence "Error! Bookmark not defined" has been removed.

The authors apologize for this error and state that this does not change the scientific conclusions of the article in any way. The original article has been updated.

Copyright (๑ 2020 Vann Jones and O'Kelly. This is an open-access article distributed under the terms of the Creative Commons Attribution License (CC BY). The use, distribution or reproduction in other forums is permitted, provided the original author(s) and the copyright owner(s) are credited and that the original publication in this journal is cited, in accordance with accepted academic practice. No use, distribution or reproduction is permitted which does not comply with these terms. 